\title{
RESPONSABILIDADE COMPARTILHADA DE RESIIDUOS SÓLIDOS: REFLEXÕES DA IMPLEMENTAÇÃO NO MUNICÍPIO DE TERESINA-PI
}

THE SHARED RESPONSIBILITY OF SOLID WASTE MANAGEMENT: REFLECTIONS ON THE IMPLEMENTATION IN THE MUNICIPALITY OF TERESINA-PI

Luiza Gabrielle de Sousa Alves

Acadêmica do curso de Bacharelado em Administração pela Universidade Estadual do Piauí (Teresina/Brasil).

E-mail: luizagsalves013@gmail.com

\section{Ana Raissa Alcântara Noleto}

Acadêmica do curso de Bacharelado em Administração pela Universidade Estadual do Piauí (Teresina/Brasil).

E-mail: contato.raissaadm@gmail.com

\section{Emanuel Alcântara da Silva}

Mestrando pelo Programa de Pós-Graduação em Administração de Empresas da Universidade de Fortaleza (Fortaleza/Brasil). Acadêmico do curso de Bacharelado em Administração pela Universidade Estadual do Piauí (Teresina/Brasil).

E-mail: emanuelalcantara26@gmail.com

\section{Helano Diógenes Pinheiro}

Doutor pelo Programa de Pós-Graduação em Administração da Universidade Federal do Rio Grande do Norte (Natal/Brasil). Professor do curso de Bacharelado em Administração da Universidade Estadual do Piauí (Teresina/Brasil).

E-mail: helanodp22@gmail.com 


\section{RESUMO}

A implementação da Lei n 12.305/10, que instituiu a Política Nacional de Resíduos Sólidos (PNRS), estabeleceu a regulamentação para o manejo de resíduos sólidos no país. Com a determinação das diretrizes para o gerenciamento compartilhado de resíduos, a PNRS esclareceu as atribuições e responsabilidades da sociedade, do setor público e do setor privado dentro do sistema de Logística Reversa brasileiro. O presente artigo busca analisar as medidas adotadas no município de Teresina-PI para atender as recomendações da Lei $n^{\circ}$ 12.305/10. Abordando o princípio da responsabilidade compartilhada, o objetivo geral desta pesquisa consiste em realizar o mapeamento e análise dos atores privados envolvidos na coleta, transporte e destinação de resíduos oriundos dos grandes geradores, de acordo com o capítulo III da supracitada lei. Considerando ainda a importância do setor público, a pesquisa pretende realizar uma análise da legislação municipal e das políticas públicas desenvolvidas para o gerenciamento de resíduos. Como principais resultados, observa-se a necessidade de intensificação na fiscalização e controle do manejo de resíduos no município. Nota-se que os setores envolvidos enfrentam dificuldades para o desenvolvimento de sistemas de logística reversa eficientes. Vale ressaltar que a produção científica pode auxiliar no planejamento e desenvolvimento de planos de ação para gestão de resíduos sólidos.

Palavras-chave: Logística Reversa. Política Nacional de Resíduos Sólidos (PNRS). Responsabilidade Compartilhada. Geradores de Resíduos Sólidos.

\section{ABSTRACT}

The implementation of Law $n^{\circ}$. 12.305/10, which instituted Brazil's National Solid Waste Policy (PNRS), established the regulation for the management of solid waste in the country. With the determination of the guidelines concerning shared waste management, PNRS clarified the roles and responsibilities of society, the public sector, and the private sector within the reverse logistics system in Brazil. This article seeks to analyze the measures adopted in the municipality of Teresina-PI in order to meet the recommendations of Law $\mathrm{n}^{\circ}$. 12.305/10. The general objective of this study is to carry out the mapping and analysis of the private actors involved in the collection, transportation, and disposal of waste from large generators, by addressing the principle of shared responsibility, and in accordance with Chapter III of the aforementioned law. Considering also the importance of the public sector, the research intends to carry out an analysis of the municipal legislation and public policies developed concerning waste management. As the main results have shown, there is a need to intensify the inspection and control of waste management in the municipality. It is noted that the sectors involved face difficulties in the development of efficient reverse logistics systems. It is worth mentioning that scientific production is able to assist in the planning and development of action plans for solid waste management.

Keywords: Reverse Logistics. National Solid Waste Policy (PNRS). Shared Responsibility. Solid Waste Generators. 


\section{INTRODUÇÃO}

A evolução dos sistemas produtivos, a intensificação do consumo e o crescimento populacional contribuíram para o aumento na geração de resíduos, ocasionando no comprometimento da qualidade de vida da sociedade e no agravamento dos problemas ambientais. As medidas sustentáveis adotadas acabam sendo insuficientes diante do elevado volume de resíduos descartados. Além disso, a ausência de políticas públicas efetivas favorece a destinação final inadequada.

Considerando o contexto acima, pode-se dizer que a Logística Reversa surgiu diante da necessidade do desenvolvimento de sistemas de produção mais sustentáveis. Com a instauração dos processos de reaproveitamento e destinação de resíduos, a Logística Reversa estabeleceu que a gestão deve organizar estratégias e ações para produção de baixo impacto ambiental.

No Brasil, visando a determinar as práticas e políticas adequadas para o manejo de resíduos sólidos, foi instituída a Lei $n^{\circ}$ 12.305/10 (regulamentada pelo Decreto $n^{\circ}$ 7.404, de 23 de dezembro de 2010), que criou a Política Nacional de Resíduos Sólidos (PNRS). A PNRS estabeleceu metas para erradicação dos chamados "lixões", a classificação dos resíduos sólidos, determinou as diretrizes para responsabilidade compartilhada e instituiu os planos de gestão integrada (nos âmbitos nacional, estadual e municipal).

O setor público tornou-se o principal agente regulamentador e fiscalizador das práticas do sistema de gestão de resíduos. A PNRS determinou que estados e municípios devem desenvolver planos de gestão de resíduos, os quais devem conter medidas para a disposição final ambientalmente adequada dos resíduos (BRASIL, 2010a).

Com a instituição do princípio da responsabilidade compartilhada, a supracitada lei determinou que os grandes geradores realizem a destinação correta dos resíduos oriundos dos sistemas de produção. Visando a adequação às determinações legais, os grandes geradores de resíduos têm recorrido a outras organizações para realização do recolhimento dos resíduos sólidos produzidos. Diante desse cenário, surge o mercado dos atores privados, responsáveis pelo segundo nível da rede de logística reversa.

Passados aproximadamente 10 (dez) anos da implementação da Lei n 12.305/10, observase que o problema no manejo de resíduos sólidos ainda persiste. De acordo com dados da Associação Brasileira de Empresas de Limpeza Pública e Resíduos Especiais (ABRELPE, 2019), estima-se que no ano de 2018 foram geradas 79 milhões de toneladas de resíduos sólidos, representando um aumento de aproximadamente $1 \%$ em relação ao ano anterior.

A ABRELPE (2019) destaca ainda que, do universo analisado, 6,3 milhões de toneladas de resíduos não foram coletadas junto aos locais de geração. Segundo o Panorama, a região Nordeste apresentou o 
menor índice na cobertura de coleta de resíduos sólidos. Ademais, observou-se que na região, a maioria dos resíduos coletados são destinados a aterros controlados e lixões.

De acordo com dados do Plano Municipal de Gestão Integrada de Resíduos Sólidos (PMGIRS) de Teresina (PMT, 2018), até o final do ano de 2032, estima-se que serão geradas 650 toneladas de resíduos por dia no município. O Plano Municipal (PMT, 2018) destaca ainda que a média de resíduos sólidos urbanos gerados por cada habitante corresponde a 1,53 Kg por dia.

Tendo em vista este cenário, se pretende analisar os impactos dos mecanismos previstos na Lei nº 12.305/10. Este artigo objetiva analisar o gerenciamento de resíduos com base na responsabilidade do gerador ou responsabilidade compartilhada. Ademais, busca-se mapear os atores privados responsáveis pela coleta, transporte e destinação de resíduos oriundos dos grandes geradores, de acordo com o capítulo III da Lei n 12.305/10. Para alcançar os objetivos estabelecidos, a pesquisa explora as medidas adotadas no município de Teresina-PI para atender as recomendações da supracitada lei e relacionar as situações que exigem a formulação de plano de gerenciamento de resíduos sólidos (conforme especificado no artigo 20 da lei 12.305/10) com a relação das empresas autorizadas.

\section{FUNDAMENTAÇÃO TEÓRICA}

Nesta seção serão discutidos tópicos referentes à implementação da Lei n 12.305/10 e a relação entre as práticas de Logística Reversa e a responsabilidade compartilhada dos resíduos sólidos.

\subsection{LOGÍSTICA REVERSA E A IMPLEMENTAÇÃO DA LEI N 12.305/10}

Tendo em vista a necessidade de desenvolvimento de processos voltados para destinação e reaproveitamento de resíduos, podendo ou não ocorrer a reincorporação dos mesmos ao sistema produtivo (ALVES, 2016, p. 113), surge a chamada Logística Reversa, caracterizada como "a parte da logística que gerencia os recursos e processos referentes aos fluxos reversos." (CORRÊA; XAVIER, 2013, p. 5).

No Brasil, em razão do crescimento no quantitativo dos resíduos gerados, foi implementada a Lei n 12.305/10, que estabeleceu a Política Nacional de Resíduos Sólidos (PNRS). Segundo Corrêa e Xavier (2013, p. 80), no país, a referida Lei se caracteriza como "o principal instrumento regulamentador que define o conceito e a implementação da Logística Reversa (...).."

A Política Nacional de Resíduos Sólidos (PNRS) define a Logística Reversa como o

Instrumento de desenvolvimento econômico e social caracterizado por um conjunto de ações, procedimentos e meios destinados a viabilizar a coleta e a restituição dos resíduos sólidos ao setor empresarial, para reaproveitamento, em seu ciclo ou em 
outros ciclos produtivos, ou outra destinação final ambientalmente adequada (BRASIL, 2010a).

De acordo com Macêdo e Rohlfs (2013, p. 8) "a implantação dos sistemas de logística reversa deve ser feita de forma independente dos serviços públicos de limpeza urbana e manejo de resíduos sólidos". A instituição da PNRS visou a integrar o poder público, a sociedade civil e a iniciativa privada ao instituir as diretrizes relativas à "gestão integrada e ao gerenciamento de resíduos sólidos, incluindo os perigosos, às responsabilidades dos geradores e do poder público e aos instrumentos econômicos aplicáveis." (BRASIL, 2010a).

Destaca-se que o processo de retorno dos resíduos ao sistema de cadeia reversa envolve uma grande dispersão dos mesmos, o que torna mais econômico um sistema de coleta e reaproveitamento, ou destinação final, intermediado por empresas especializadas. Segundo Corrêa e Xavier (2013), a gestão de cadeias reversas favorece os envolvidos pelo fato da vantagem comercial em ambos os aspectos.

No entanto, Mariath e Figueiró (2018, p. 138) apontam que "é notável a ampliação do debate sobre a logística reversa nas corporações, trazendo esta evidente preocupação e maior importância do tema nas organizações, contudo, ainda não é assunto prioritário.". Nesse contexto, Mariath e Figueiró (2018) destacam que as falhas na fiscalização da Lei n 12.305/10, bem como a falta de conhecimento quanto à estruturação do um sistema de Logística Reversa, contribuem para o baixo comprometimento das empresas na destinação correta dos resíduos.

\subsection{RESPONSABILIDADE COMPARTILHADA DE RESÍDUOS SÓLIDOS}

Com a implementação da Lei nº 12.305/10, ficou atribuída às organizações a responsabilidade pelos resíduos que geram. No intuito de garantir a efetividade de suas ações, os geradores têm recorrido a outras organizações para o recolhimento dos resíduos sólidos produzidos.

Alguns países, como o Brasil, optaram pela responsabilidade compartilhada, segundo a qual todos os agentes da cadeia são corresponsáveis pela gestão ambientalmente adequada dos resíduos. Isso tem possibilitado a consolidação de ações por acordos setoriais, dos quais participam as organizações produtoras, as empresas, recicladoras, a sociedade, academia e o governo. (CORRÊA; XAVIER, 2013, p. 188).

Com base no contexto acima, bem como no art. 20 da Lei n 12.305/10, entende-se que a prestação de serviços de coleta e destinação de resíduos sólidos enquadra-se na denominada "responsabilidade do gerador" ou "responsabilidade compartilhada" que estabelece às pessoas físicas ou jurídicas obrigação de elaborar seu plano de gerenciamento de resíduos sólidos. Ressalta-se também que a responsabilidade 


\title{
Gestãoe \\ Desenvolvimento
}

e-ISSN: 2446-6875

p-ISSN: $1807-5436$

e obrigatoriedade de planos de manejo, conforme o art. 27 da PNRS (BRASIL, 2010a), atribui aos atores a responsabilidade "pela implementação e operacionalização integral do plano de gerenciamento de resíduos sólidos aprovado pelo órgão competente".

\begin{abstract}
Destaca-se que o princípio da responsabilidade compartilhada possibilita, diretamente ou por analogia, importantes avanços em outras matérias, como da responsabilização solidária dos causadores de quaisquer formas de poluição. Nesse contexto, ressaltase que, a Lei $n^{\circ}$. 12.305/10 ao estabelecer em seu artigo 27 , caput e $\S 1^{\circ}$. que os agentes responsáveis pelo plano de gerenciamento de resíduos sólidos não terão sua responsabilidade excluída no caso de contratação de serviços de coleta, armazenamento, transporte ou destinação final de resíduos sólidos, ou disposição final de rejeitos em função do gerenciamento inadequado dos respectivos resíduos ou rejeitos, evidencia a aplicabilidade da solidariedade na responsabilidade civil por danos ambientais. (SINNOTT, 2012, p. 20).
\end{abstract}

O setor público configura-se como o principal agente regulamentador e fiscalizador das práticas de gestão de resíduos. Segundo Mancini, Ferraz e Bizzo (2012, p. 348), "[...] a legislação brasileira aponta para o princípio do poluidor-pagador, responsabilizando cada gerador pelo seu resíduo.". Segundo os parâmetros estabelecidos pela Política Nacional de Resíduos Sólidos (PNRS), cabe aos municípios articular a efetivação, organização e prestação direta ou indireta dos serviços envolvendo resíduos sólidos.

Moreira et al. (2016, p. 1452) destacam que

O que se pretende com os mecanismos previstos na PNRS, dentre os quais os acordos setoriais, destinados à promoção da responsabilidade ambiental pós-consumo é a concretização da orientação do princípio do poluidor-pagador, garantindo-se a justa e equitativa distribuição dos ônus e de bônus relativos à produção de determinados bens ao longo de sua cadeia de produção e consumo e, consequentemente, evitando a socialização dos respectivos custos ambientais.

Em termos conceituais, o desenvolvimento da pesquisa aconteceu com base no princípio do poluidorpagador, instituído pela Lei no 12.305/10, no inciso II do art. $6^{\circ}$. Tendo avançado na área ambiental como a melhor forma de solucionar o problema da poluição, "o princípio do poluidor-pagador, como instituição basilar que objetiva a contenção do dano ambiental através de um caráter preventivo-repressivo, ao ser utilizado por várias nações, fortalece e influencia a legislação infraconstitucional brasileira." (BORGES, MELLO; OLIVEIRA, 2010, p. 204). 


\section{Gestãoe \\ Desenvolvimento}

e-ISSN: 2446-6875

p-ISSN: $1807-5436$

Figura 1 - Responsabilidade compartilhada

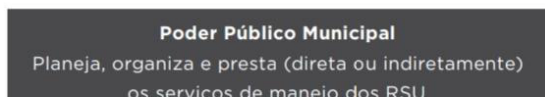

os serviços de manejo dos RSU.
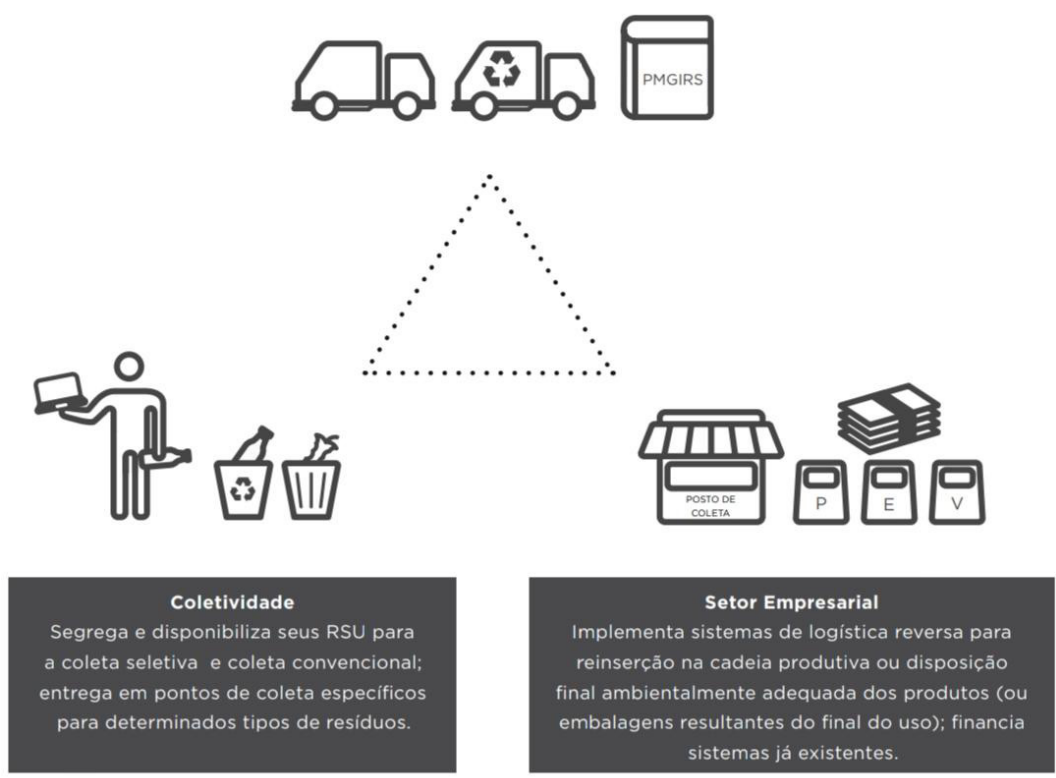

Fonte: Instituto Ethos de Empresas e Responsabilidade Social (p. 27, 2015).

O processo de gestão de resíduos sólidos envolve diversos aspectos e agentes para desenvolvimento das ações. Nesse sentido, Torres et al. (2016, p. 148) destaca que "a gestão de resíduos sólidos é compreendida como mecanismo viável e capaz de abranger as atividades referentes à tomada de decisões estratégicas e à organização do setor para esse fim, envolvendo instituições públicas, políticas, instrumentos e meios".

No princípio da responsabilidade compartilhada, ressalta-se que o gerador de resíduos domiciliares tem sua responsabilidade cessada na medida em que faz a disposição adequada dos resíduos para coleta. Ou seja, sua responsabilidade seria ampliada apenas nos casos que estivesse lidando com um dos resíduos especificados nos artigos 13 e 20 da PNRS. Nas situações de geração de resíduos advindo do consumo familiar, a obrigação é pela separação e acondicionamento adequado para realização da coleta domiciliar e a segregação no caso de resíduos recicláveis, conforme estabelece o artigo 35 da PNRS (BRASIL, 2010a).

Ao analisar o sistema "Pay-As-You-Throw", abreviado como PAYT, Oliveira (2018, p. 20) comenta sua semelhança com o princípio do poluidor-pagador e destaca que o Plano Nacional de Resíduos Sólidos, estabelecido pela PNRS, "apresenta Incentivos Econômicos como uma ferramenta aplicada à gestão de 


\section{Gestãoe \\ Desenvolvimento}

e-ISSN: 2446-6875

p-ISSN: $1807-5436$

resíduos com a função de financiar os serviços de limpeza pública, orientar o comportamento da população e responsabilizar os impactos gerados pela quantidade de resíduos produzidos".

Nesse sentido, Oliveira (2018) destaca que a PNRS foi o principal meio para formalização dos pilares da gestão integrada de resíduos sólidos, proporcionando um ganho em escala por meio de uma gestão regionalizada. Segundo Oliveira (2018), a gestão regionalizada permite a redução de custos com limpeza urbana em razão da sinergia entre municípios no processo de compartilhamento do sistema de coleta, tratamento e destinação de resíduos sólidos.

Para o estabelecimento do sistema de Logística Reversa previsto na PNRS, os diferentes stakeholders (setor público, setor privado e sociedade) devem interagir constantemente (ver Figura 1). Segundo a PNRS, o setor público ficou responsável por consolidar o incentivo do desenvolvimento social e econômico menos prejudicial ao meio ambiente. Com isso, os municípios obrigatoriamente necessitam contribuir com a efetivação, organização e prestação direta ou indireta dos serviços envolvendo resíduos sólidos.

Neste contexto, o artigo analisou o cenário do Município de Teresina com base no Decreto n 18.061, de 18 de outubro de 2018, que regulamenta a prestação de serviços de coleta e destinação final por meio do cadastramento de empresas transportadoras de resíduos sólidos (TERESINA, 2018a). 0 quadro abaixo possui a listagem e descrição da legislação municipal relacionada ao assunto em estudo. 


\section{Gestãoe \\ Desenvolvimento}

e-ISSN: 2446-6875

p-ISSN: 1807-5436

Quadro 1 - Detalhamento da legislação municipal

\begin{tabular}{|c|c|}
\hline LEIS & ASSUNTOS \\
\hline Lei n³ 3.544/2006 & $\begin{array}{l}\text { Autoriza o Poder Executivo Municipal a criar o Programa de Reciclagem de Lixo em todos os } \\
\text { órgãos da administração direta e indireta do município. }\end{array}$ \\
\hline Lei n³.646/2007 & Institui o Código Sanitário do município de Teresina, e dá outras providências. \\
\hline Lei n³.923/2009 & $\begin{array}{l}\text { Dispõe sobre a implantação da coleta de lixo reciclável nos condomínios residenciais e } \\
\text { comerciais; postos de gasolina e afins localizados no município de Teresina, e dá outras } \\
\text { providências. }\end{array}$ \\
\hline Lei $n^{\circ} 4.224 / 2012$ & Dispõe sobre a criação do Disk Lixo no município, e dá outras providências. \\
\hline Lei $n^{\circ} 4.474 / 2013$ & Institui o "Programa Lixo Zero", no âmbito do município de Teresina, e dá outras providências. \\
\hline Lei $n^{\circ} 4.684 / 2015$ & $\begin{array}{l}\text { Institui diretrizes acerca da criação do programa de coleta seletiva de resíduos sólidos e } \\
\text { inclusão social dos catadores de materiais recicláveis - Pró-catador, no município de Teresina, } \\
\text { e dá outras providências. }\end{array}$ \\
\hline Lei $n^{\circ} 4.973 / 2016$ & $\begin{array}{l}\text { Institui os objetivos e metas para o Plano Municipal de Saneamento } \\
\text { Básico do município de Teresina e dá outras providências. }\end{array}$ \\
\hline Lei $n^{\circ}$ 4.974/2016 & Institui o novo Código Tributário do município de Teresina e dá outras providências. \\
\hline Lei $n^{\circ} 5.229 / 2018$ & $\begin{array}{l}\text { Institui o Programa de Sustentabilidade Ambiental na rede municipal de ensino, e dá outras } \\
\text { providências. }\end{array}$ \\
\hline $\begin{array}{l}\text { Decreto } n^{\circ} \\
17.733 / 2018\end{array}$ & $\begin{array}{l}\text { Institui e regulamenta o Plano Municipal de Gestão Integrada de Resíduos Sólidos - PMGIRS } \\
\text { do Município de Teresina. }\end{array}$ \\
\hline $\begin{array}{l}\text { Decreto } n^{\circ} \\
18.061 / 2018\end{array}$ & Institui o cadastramento de empresas responsáveis pelo transporte de resíduos sólidos. \\
\hline $\begin{array}{l}\text { Decreto } n^{\circ} \\
18.062 / 2018\end{array}$ & $\begin{array}{l}\text { Regulamenta o art. 120, } \S 3^{\circ} \text {, da Lei Complementar n 3.610/2007 (Código de Posturas), } \\
\text { para disciplinar o cadastramento das áreas de destinação de resíduos sólidos, no âmbito do } \\
\text { Município de Teresina, e dá outras providências. }\end{array}$ \\
\hline
\end{tabular}

\section{Fonte: Adaptado de COELHO (p. 60, 2019).}

Conforme dispõe o art. 26 da Lei 12.305/10, o Plano Municipal de Gestão Integrada de Resíduos Sólidos (PMGIRS) baliza as ações do poder público para organização e prestação dos serviços limpeza urbana e manejo de resíduos sólidos (BRASIL, 2010a). De acordo com Coelho (2019, p. 63), o Plano Municipal de Gerenciamento Integrado de Resíduos Sólidos (PMGIRS) de Teresina (ver Quadro 1)

(...) classifica os resíduos também quanto à identificação do gerador, em que há a geração difusa, que são os produzidos, individual ou coletivamente, por geradores dispersos e não identificáveis, por ação humana, animal ou por fenômenos naturais, 


\begin{abstract}
abrangendo os resíduos sólidos domiciliares, os resíduos sólidos pós-consumo e aqueles provenientes da limpeza pública. Há também a geração determinada, que são os produzidos por gerador específico e identificável. Tal classificação permite ao poder público municipal taxar os geradores de resíduos sólidos identificáveis, de forma a manter a autossustentação do sistema.
\end{abstract}

A análise do sistema teresinense abordou as chamadas empresas de segundo nível, ou seja, aquelas empresas autorizadas a atuar na coleta, transporte, segregação e destinação de resíduos em relações privadas, ou seja, ofertam seus serviços no âmbito municipal sem intermediação ou remuneração por parte do poder público. Tais serviços atendem à denominada "responsabilidade do gerador" ou "responsabilidade compartilhada" tratada pela Lei n 12.305/10.

O estudo busca nestas empresas uma descrição de como está se formando o mercado de serviços relacionados ao retorno de bens pós-consumo, material base para o processo de reaproveitamento dos resíduos produzidos no espaço urbano (LEITE, 2009; ROGERS; TIBBEN-LEMBKE, 1998). As empresas cadastradas junto ao poder público municipal para execução do serviço de coleta e transporte de resíduos sólidos, desde que não vinculadas por contrato e remuneradas pelo poder público, constituem o objeto do presente estudo. Dessa forma, procurou-se identificar como está sendo implementado o serviço de coleta dos resíduos junto aos geradores que possuem responsabilidade.

\title{
3 METODOLOGIA
}

A pesquisa buscou observar, registrar, analisar e relacionar a formação de um setor de serviços privados relacionados à coleta de resíduos na cidade de Teresina-PI, o que a caracteriza como uma pesquisa descritiva. De acordo com Cervo e Bervian (2002, p. 67), neste tipo de pesquisa "trata-se do estudo e da descrição das características, propriedades ou relações existentes na comunidade, grupo ou realidade pesquisada".

Durante a revisão bibliográfica, foram coletados autores com obras datadas dos anos de 2000 a 2019. As obras selecionadas referem-se ao objeto de estudo e abordam assuntos como a "responsabilidade compartilhada" e a "responsabilidade do gerador de resíduos", o conceito e as aplicações do termo "poluidor-pagador", da logística reversa, do direito ambiental, a Política Nacional de Resíduos Sólidos PNRS (Lei 12.305/10) e o Plano de Gerenciamento de Resíduos Sólidos (PGRS).

Durante o período de (três) meses, além da realização da revisão de literatura, ocorreu a revisão do material produzido em pesquisas científicas anteriores, a partir das diretrizes da Lei nº 12.305/10, com 
o objetivo de compreender as medidas adotadas pelo poder público para adequação da responsabilidade do gerador à PNRS.

O estudo buscou captar o desenvolvimento do mercado privado de coleta de resíduos na cidade de Teresina-PI, identificando a implementação do serviço junto aos geradores que possuem responsabilidade. Com base nas informações coletadas no site da Secretaria Municipal de Desenvolvimento Urbano e Habitação (SEMDUH), órgão responsável pela gestão do sistema municipal de logística reversa (BRASIL, 2010a), pode-se constatar que as empresas do sistema de logística reversa teresinense atuam na coleta extradomiciliar, realizando o transporte, segregação e destinação de resíduos não-perigosos e perigosos, por meio de relações privadas com as entidades geradoras.

Como fonte de informações, utilizou-se de dados documentais para uma análise da ação do poder público na implementação da ação em estudo e um retorno à pesquisa bibliográfica, desta vez manifesta na identificação de materiais publicados na internet noticiando a ação pública ou sua repercussão. Para tanto, foram selecionados os principais portais de notícias teresinenses em número de acessos de internautas, entre eles: o Portal Cidade Verde, Portal O Dia, 180 Graus, Meio Norte, G1/PI, GP1, que são os mais acessados de acordo com pesquisas em comunicação (CARVALHO; CARVALHO, 2018; VIANA; COELHO; RÊGO, 2011) e com o Ranking da Alexa da Amazon (EM FOCO, 2020; VOZ DO PIAUÍ, 2020).

A utilização de informações da internet deve ser feita com cuidado, pois "[...] procurar e recuperar informações na internet é muito mais problemático do que procurar em um banco de dados bibliográfico. Não há campos padronizados, nenhuma hierarquia cuidadosamente definida, [...], nenhum critério de seleção e, em geral, nenhuma regra[...]" (COOPER; SCHINDLER, 2011, p. 129). Os dados utilizados na pesquisa são predominantemente de fontes secundárias e terciárias, caracterizadas por serem, respectivamente, interpretações de dados primários ou ainda uma referência a estudos que utilizaram dados secundários. De acordo com Michel (2009, p. 65), os dados secundários podem ser "coletados através de análise documental, ou seja, em documentos, relatórios, livros, revistas, jornais, sites, etc.."

Segundo Cooper e Schindler (2011, p. 104), "[...] enciclopédias, livros, manuais, artigos de revistas e jornais e a maioria das notícias são consideradas fontes secundárias de informação". Quanto ao local de busca destas informações, utiliza-se cada vez mais a internet, pois os documentos on-line são cada vez mais comuns, tanto os documentos institucionais quanto informações transmitam por meios de comunicação diversos, porém estas informações são complicadas de coletar e interpretar por não estarem vinculadas e organizadas a uma base de dados. Em casos nos quais os processos sociais ainda estão se desenvolvendo, a busca na rede por informações ainda difusas pode fornecer informações sobre a ocorrência do processo, embora não se possa realizar análises ou correlações mais aprofundadas. 
Coletou-se as informações por meio da utilização de dados secundários, buscou-se informações referentes a coleta de resíduos sólidos, coleta seletiva ou simplesmente resíduos sólidos nos veículos noticiosos de teresina, bem como identificar empresas com "atividade de coleta de resíduos" a partir de lista disponibilizada pela Secretaria do Meio Ambiente (SEMAM) e pela relação de empresas cadastradas pela Secretaria Municipal de Desenvolvimento Urbano e Habitação (SEMDUH) e Coordenação Especial de Limpeza Urbana (CELIMP).

Com isso, foi realizado o mapeamento de 5 (cinco) empresas que são envolvidas na coleta, transporte e destinação de resíduos oriundos de geradores privados, conforme o capítulo III da Lei n 12.305/10. Devido às medidas de isolamento social, ocasionadas pelo vírus COVID-19, não se efetuou coletas de dados in loco. Chegou-se a elaborar um questionário on-line e a se identificar as empresas habilitadas a prestar o serviço em ofício da Secretaria do Meio Ambiente (SEMAM). Porém, o fechamento do varejo de contato influiria na coleta de informações consistentes sobre a aplicação da norma legal e, dessa forma, preferiu-se manter o artigo com base em informações públicas e privadas coletadas em meios noticiosos no período de 2019 a junho de 2020.

Considerando as determinações do art. $1^{\circ}, \S 1^{\circ}, \S 2^{\circ}$ e $\S 3^{\circ}$ do Decreto $N^{\circ} 18061$, de 18 de outubro de 2018 (ver Quadro 1), verificou-se que as 5 (cinco) empresas analisadas possuem autorização para realizar o transporte de resíduos sólidos, têm sede no município e estão devidamente cadastradas na Secretaria Municipal de Desenvolvimento Urbano e Habitação (SEMDUH).

Com base nos dados coletados nas relações citadas anteriormente, realizou-se a triagem das empresas de acordo com o tipo de atividade desenvolvida e o tipo de resíduos coletados. Ademais, para aprofundamento da pesquisa, foram selecionados dados dos sites institucionais das empresas. Considerados todos os dados recolhidos, foi realizada a comparação entre as empresas coletadas.

\section{RESULTADOS E DISCUSSÃO}

Esta seção apresenta a exploração das medidas adotadas no município de Teresina-PI para atender as recomendações da Lei n 12.305/10, bem como o mapeamento e análise dos atores privados envolvidos na coleta, transporte e destinação de resíduos oriundos dos grandes geradores.

\subsection{AÇÕES DO PODER PÚBLICO MUNICIPAL}

A Política Nacional de Resíduos Sólidos (PNRS) proporcionou o avanço da Logística Reversa nos âmbitos público e privado, contribuindo para a transparência no gerenciamento de resíduos sólidos. Dentro desse contexto, a denominada responsabilidade do gerador ou responsabilidade compartilhada, 


\section{Gestãoe \\ Desenvolvimento}

e-ISSN: 2446-6875

p-ISSN: $1807-5436$

tratada no artigo 20 da Lei n 12.305/10, estabelece que pessoas físicas ou jurídicas estão obrigadas a elaborar seu Plano de Gerenciamento de Resíduos Sólidos (PGRS). Ademais, a Lei atribuiu aos estados e municípios a função de regulamentar e fiscalizar as práticas de coleta e destinação final de resíduos.

Considerando os critérios já presentes e consolidados no contexto brasileiro, a Política Nacional de Resíduos Sólidos (PNRS) instituiu várias classificações para os resíduos, sendo elas: quanto à destinação, quanto à origem, quanto à logística e quanto ao grau de periculosidade (BRASIL, 2010a). No artigo 27 da Lei n 12.305/10, são estabelecidos os parâmetros quanto à responsabilidade e obrigatoriedade de planos de manejo para estabelecimentos que lidam com resíduos perigosos ou resultantes de processos produtivos.

Por meio de solicitação à Secretaria Municipal de Desenvolvimento Urbano e Habitação (SEMDUH), obteve-se o Relatório Quantitativo do Programa de Educação Ambiental e a relação de resíduos removidos durante o ano de 2019. O referido possui informações a respeito da Coleta Seletiva e dos Pontos de Recebimento de Resíduos - PRR's.

O relatório não apresentava informações a respeito das empresas privadas, no entanto contribuiu para a visualização das ações governamentais para a instituição e gestão do sistema municipal de logística reversa. Contudo, com base nas informações presentes na relação de resíduos removidos durante o ano de 2019, pode-se visualizar a situação da coleta de resíduos feita no município. 0 gráfico a seguir foi desenvolvido conforme dados presentes na referida relação.

Gráfico 1 - Resíduos removidos durante o ano de 2019

\section{Resíduos Removidos no Ano de 2019}

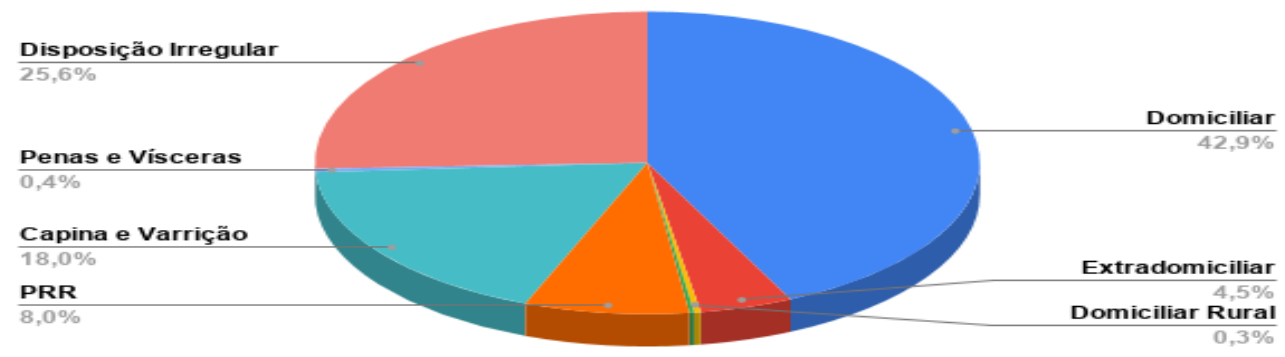

Fonte: Elaborado pelos autores com base nos dados obtidos da Secretaria Municipal de Desenvolvimento Urbano e Habitação (SEMDUH), 2019.

Conforme citado anteriormente, o papel do setor público consiste em consolidar o incentivo do desenvolvimento social e econômico de baixo impacto ambiental. Tendo em vista os parâmetros 
estabelecidos pela PNRS, os municípios obrigatoriamente necessitam contribuir com a efetivação, organização e prestação direta ou indireta dos serviços envolvendo resíduos sólidos.

No âmbito teresinense, a instituição e gestão do sistema municipal de logística reversa (BRASIL, 2010b) envolve a coleta de resíduos domiciliares, a varrição dos logradouros públicos, a coleta seletiva e o monitoramento dos aterros, fica sob responsabilidade da Secretaria Municipal de Desenvolvimento Urbano e Habitacional (SEMDUH), enquanto que a aprovação dos planos e a autorização de empresas para atuarem com atividade de potencial de impacto ambiental, incluindo o manejo de resíduos, requer um processo de licenciamento de responsabilidade da Secretaria Municipal de Meio Ambiente (SEMAM).

Em cumprimento à Política Nacional de Resíduos Sólidos (PNRS), o município estabeleceu que os resíduos oriundos dos grandes geradores pertencem à coleta extradomiciliar, ou seja, de responsabilidade dos produtores. Por meio do Decreto No 18061, de 18 de outubro de 2018, a Secretaria Municipal de Desenvolvimento Urbano e Habitacional (SEMDUH) instituiu o cadastramento de empresas responsáveis pelo transporte de resíduos sólidos (coleta extradomiciliar), ou seja, os atores privados que atuam no segundo nível da rede de logística reversa. Considerando as determinações do art. $1^{\circ}, \S 1^{\circ}, \S 2^{\circ}$ e $\S 3^{\circ}$ do Decreto, as empresas devem possuir sede no município e estar devidamente cadastradas na SEMDUH.

Vale destacar que, caso a Secretaria Municipal de Desenvolvimento Urbano e Habitacional (SEMDUH) realize a coleta de resíduos não enquadrados dentro da competência legal do município, por serem considerados extradomiciliares, conforme artigo 272 da Lei Complementar n 4.974, de 26 de dezembro de 2016 (Código Tributário Municipal), acontecerá a cobrança da Taxa de Coleta, Transporte e Disposição Final de Resíduos Sólidos Extradomiciliares - TCRE (TERESINA, 2016).

O Decreto No 18.062/2018, de 18 de outubro de 2018 (ver Quadro 1), disciplinou o cadastramento das áreas de destinação de resíduos sólidos, no âmbito do Município de Teresina (TERESINA, 2018b), em conformidade com as determinações do artigo $18, \S 4^{\circ}$ da Lei $n^{\circ} 12.305 / 10$. Atualmente, no município, a disposição final dos resíduos sólidos acontece em aterro controlado.

Considerando as recomendações do Plano Municipal de Gerenciamento Integrado de Resíduos Sólidos (PMGIRS), instituído pelo Decreto n 17.733/2018, pode-se observar que o poder público tem realizado ações voltadas para a Coleta Seletiva, com a instalação de Pontos de Entrega Voluntária (PEV's) e Pontos de Recebimentos de Resíduos (PRR's). Ressalta-se que cooperativas e ONGs têm contribuído para o recolhimento de resíduos sólidos. No entanto, segundo Coelho (2019, p. 93), "quanto à efetividade das ações estabelecidas no Plano, o município apresenta resultados inadequados.", tendo em vista que o descarte de resíduos sólidos ainda acontece em aterro controlado.

A aplicação de taxas ou multas pode funcionar como um instrumento de controle sobre a geração de resíduos. Neste sentido, visando reduzir o descarte irregular de resíduos, o poder legislativo municipal 
implementou a Lei n 4.474/13 (ver Quadro 1), que instituiu o Programa "Lixo Zero". Conforme disposto no art. $6^{\circ}$, parágrafo único, da Lei $n^{\circ} 4.477 / 13$, os recursos provenientes das multas são destinados à educação e áreas de interesse social (TERESINA, 2013). Ressalta-se que, conforme dados extraídos do site da Prefeitura Municipal de Teresina, as pessoas jurídicas representam os maiores índices de autuações do Programa "Lixo Zero" (PMT, 2020).

Vale destacar que, conforme dados extraídos do site da Prefeitura Municipal de Teresina (PMT, 2020), apenas em janeiro de 2020, houve um crescimento de $44,55 \%$ nas autuações do Programa "Lixo Zero". Constatou-se que a maioria das infrações são cometidas por pessoas jurídicas, representando um percentual de $54 \%$ no universo coletado.

\subsection{REFLEXOS DA IMPLEMENTAÇÃO DA COLETA PRIVADA}

As determinações da PNRS, constantes na seção V, art. 20 ao 24 da Lei no 12.305/10, estabelecem que os geradores de resíduos sólidos são responsáveis pela elaboração do Plano de Gerenciamento de Resíduos Sólidos (PGRS), documento regulamentador das medidas necessárias para o manejo dos resíduos produzidos. Contudo, todo o processo de manejo envolve uma grande dispersão de resíduos, fator que contribui para o desenvolvimento de um sistema de coleta e reaproveitamento, ou destinação final, intermediado por empresas especializadas, ou seja, as empresas que compõem o segundo nível de logística reversa.

Conforme dados extraídos do Plano Municipal de Gestão Integrada de Resíduos Sólidos (PMGIRS) de Teresina (PMT, 2018), no município existe uma quantidade considerável de grandes geradores na área urbana. Conforme citado anteriormente, o Decreto N 18061, de 18 de outubro de 2018, instituiu o cadastramento das empresas responsáveis pelo transporte de resíduos sólidos (coleta extradomiciliar) oriundos dos grandes geradores, ou seja, atores privados que atuam no segundo nível.

Com a passagem de aproximadamente 2 (dois) anos após a sanção do Decreto Municipal N 18061, de 18 de outubro de 2018, o estudo não identificou impacto relevante no mercado das empresas do segundo nivel, ou seja, as empresas autorizadas a atuar na coleta, transporte, segregação e destinação de resíduos em relações privadas, que ofertam seus serviços no âmbito municipal sem intermediação ou remuneração por parte do poder público.

Considerando a relação de empresas com "atividade de coleta de resíduos" disponibilizada pela Secretaria do Meio Ambiente (SEMAM), bem como a relação de empresas cadastradas pela Secretaria Municipal de Desenvolvimento Urbano e Habitacional (SEMDUH) /Coordenação Especial de Limpeza Pública (CELIMP), foram verificados os cadastros de 30 (trinta) empresas que realizam os serviços de coleta de resíduos sólidos. 


\section{Gestãoe \\ Desenvolvimento}

e-ISSN: 2446-6875

p-ISSN: $1807-5436$

Com base nos dados coletados (apêndice A), observa-se que a maioria das empresas desenvolvem outras atividades além da coleta, transporte, segregação e destinação de resíduos. Aparentemente, durante o processo de cadastramento, não acontece uma triagem de empresas que trabalham exclusivamente com a destinação de resíduos. Portanto, para atingir os objetivos propostos, foram selecionadas empresas que desempenhavam apenas atividades relacionadas ao manejo de resíduos.

Quadro 2 - Empresas cadastradas para coleta, transporte, segregação e destinação de resíduos

\begin{tabular}{|c|c|c|c|c|c|c|}
\hline \multirow{3}{*}{$\begin{array}{c}\text { Atores } \\
\text { Privados }\end{array}$} & \multicolumn{4}{|c|}{ CARACTERÍSTICAS DO MANEJO DE RESÍDUOS } & \multirow{2}{*}{\multicolumn{2}{|c|}{$\begin{array}{c}\text { ATIVIDADES } \\
\text { Possui atividades não } \\
\text { relacionadas ao manejo } \\
\text { de resíduos sólidos? }\end{array}$}} \\
\hline & \multirow{2}{*}{$\begin{array}{l}\text { Coleta de } \\
\text { resíduos } \\
\text { perigosos }\end{array}$} & \multirow{2}{*}{$\begin{array}{l}\text { Coleta de } \\
\text { resíduos não- } \\
\text { perigosos }\end{array}$} & \multirow{2}{*}{$\begin{array}{l}\text { Transporte e } \\
\text { disposição de } \\
\text { resíduos } \\
\text { perigosos }\end{array}$} & \multirow{2}{*}{$\begin{array}{l}\text { Transporte e } \\
\text { disposição de } \\
\text { resíduos não- } \\
\text { perigosos }\end{array}$} & & \\
\hline & & & & & Sim & Não \\
\hline Empresa 01 & & $x$ & & $x$ & & $x$ \\
\hline Empresa 02 & $x$ & $x$ & $x$ & $x$ & & $x$ \\
\hline Empresa 03 & $x$ & $x$ & $x$ & $x$ & & $x$ \\
\hline Empresa 04 & $x$ & & $x$ & & & $x$ \\
\hline Empresa 05 & $x$ & $x$ & $x$ & $x$ & & $x$ \\
\hline
\end{tabular}

Fonte: Elaborado pelos autores (2021).

Considerando as empresas identificadas (apêndice A), verificou-se 5 (cinco) empresas cujo objeto se enquadraria na coleta de resíduos empresariais (ver Quadro 2). Com base nos dados, observa-se um destaque na coleta e destinação de resíduos perigosos. Ressalta-se que, conforme disposto no art. 13 da Lei n 12.305/10, a PNRS (BRASIL, 2010a) destaca que os resíduos perigosos, são aqueles que, em razão de suas características de inflamabilidade, corrosividade, toxicidade, patogenicidade, carcinogenicidade e mutagenicidade, apresentam significativo risco à saúde pública ou a qualidade ambiental, de acordo com a lei, regulamento ou norma técnica.

Com relação a expansão territorial, apenas 2 (duas) empresas possuem filiais em outros municípios/ estados. Entre as empresas selecionadas, apenas 1 (uma) encontra-se localizada no polo industrial da cidade. Em consideração a importância do meio digital, foram verificados os sites institucionais das empresas. Todas alimentam os sites com informações básicas como listas de contatos, listas de endereços, listas com os principais clientes, dados sobre a história e sobre os tipos de serviços ofertados. Verificou-se que apenas 1 (uma) empresa não possui redes sociais. Ainda com base nos dados coletados nos sites das empresas, pode-se observar que as referidas atentem negócios e indústrias locais. Tendo 
em vista a pandemia ocasionada pelo vírus COVID-19 e medidas de isolamento social adotadas, bem como a fragilidade do mercado limitado, pode-se dizer que as empresas coletadas sofreram impactos na captação de recursos.

Constatou-se que, dentre a amostra coletada, 1 (uma) empresa teve suas atividades suspensas até o dia 31 de agosto de 2020, por determinação do Ministério Público. A medida foi adotada em virtude do processo de incineração de resíduos realizado pela empresa estar gerando poluição atmosférica, ocasionando em impactos ambientais e prejudicando a população local. A empresa encontra-se relacionada a inquérito civil público que apura possíveis irregularidades em seu funcionamento.

Além dos geradores, os atores privados que atuam no segundo nível da rede de logística reversa enfrentam dificuldades para realizar adequadamente a destinação dos resíduos. Segundo dados extraídos do Plano Municipal de Gestão Integrada de Resíduos Sólidos (PMGIRS) de Teresina (PMT, 2018), no município existem 101 pontos de disposição irregular de resíduos. Ressalta-se que a regulamentação e cadastramento das empresas em análise acontece desde o ano de 2018. No entanto, apenas em março de 2019, a Prefeitura de Municipal de Teresina deixou de realizar o manejo de resíduos sólidos extradomiciliares.

Segundo informações do Portal O Dia (2019), aproximadamente 200 estabelecimentos ainda recorriam ao serviço de coleta municipal. Entretanto, os referidos estabelecimentos foram devidamente comunicados e orientados a contratar empresas privadas para realização do manejo de seus resíduos.

Considerando as informações citadas no Gráfico 1, sobre o quantitativo pequeno de empresas especializadas na coleta de resíduos, pode-se observar que o município ainda ocupa o espaço de maior agente no sistema de logística reversa. A fiscalização junto aos geradores de resíduos acontece de maneira retraída e pode ser um dos fatores que contribuem para os índices de disposição irregular elevados. Vale pontuar que, de acordo com o Plano Municipal de Gestão Integrada de Resíduos Sólidos (PMGIRS) de Teresina (PMT, 2018), o município também realiza o cadastramento dos geradores, podendo "validálos ou não como grandes geradores passivos de coleta e taxação diferenciada.. O cadastro possibilita a definição e informação a respeito da necessidade de desenvolvimento do Plano de Gerenciamento de Resíduos Sólidos (PGRS) por parte dos geradores. Tal fator pode estar contribuindo para a estagnação do desenvolvimento do mercado em análise, tendo em vista que os grandes geradores podem não estar recorrendo ao setor privado para destinação de seus resíduos.

Observa-se que a estruturação do mercado das empresas do segundo nível do sistema de logística reversa acontece de maneira lenta. Nota-se também a ausência de inovação tecnológica no mercado. Ademais, caso não haja o fortalecimento do princípio da responsabilidade compartilhada, os avanços gerados pela Lei no 12.305/10 podem ser negligenciados. 
A produção científica a respeito dos assuntos como responsabilidade compartilhada, o conceito de poluidor-pagador, logística reversa, direito ambiental, a aplicabilidade da Lei 12.305/10, bem como a Política Nacional de Resíduos Sólidos (PNRS) é consideravelmente vasta. No entanto, são poucos que evidenciam a corresponsabilidade das empresas privadas contratadas pelas organizações geradoras. Ademais, não foram localizadas parcerias entre as empresas em análise e a comunidade acadêmica.

\section{CONSIDERAÇÕES FINAIS}

A implementação da Lei no 12.305/10, que instituiu a Política Nacional de Resíduos Sólidos (PNRS), contribuiu para uma revolução nos termos ambientais do país. A Lei estabeleceu as diretrizes de classificação e destinação dos resíduos, introduziu o conceito de Logística Reversa nas organizações, atribuiu aos estados e municípios o poder de regulamentar e fiscalizar o seu cumprimento e estabeleceu a responsabilidade compartilhada sobre os resíduos. O princípio do poluidor-pagador, instituído no inciso Il do art. $6^{\circ}$ da referida, contribuiu para imputação da responsabilidade ao gerador com relação aos custos resultantes de seus sistemas de produção.

No âmbito municipal, visando a adequar-se às medidas instauradas pela Lei $n^{0} 12.305 / 10$, 0 Decreto Municipal N 18061, de 18 de outubro de 2018, foi instituído para estabelecer o cadastramento e a fiscalização de empresas privadas para atuarem na coleta dos resíduos resultantes dos grandes geradores (coleta extradomiciliar).

O presente estudo analisou o cenário municipal após a passagem de aproximadamente 2 (dois) anos da sanção do Decreto Municipal N 18061, de 18 de outubro de 2018, bem como os impactos da Lei $n^{\circ}$ 12.305/10 e da Política Nacional de Resíduos Sólidos (PNRS) no sistema de logística reversa teresinense.

Com base nos dados coletados, constata-se que o sistema de logística reversa teresinense referente a coleta de grandes geradores ainda é incipiente. Tendo em vista que o estudo buscou analisar apenas empresas especializadas na coleta, transporte, segregação e destinação de resíduos, nota-se que a grande maioria das empresas cadastradas nos órgãos públicos realizam outras atividades além da coleta de resíduos extradomiciliares. Observa-se que tanto os geradores, como o setor privado de coleta, enfrentam dificuldades para realizar a destinação correta de resíduos, persistindo a disposição irregular dos resíduos, desafiando a atuação dos órgãos públicos. Vale destacar que no município os resíduos coletados ainda são destinados a aterros sanitários. Ademais, ao analisar os prazos estabelecidos pela PNRS, pode-se constatar que as medidas adotadas pelo município são recentes, tendo sido estabelecidas após os períodos previstos em lei. 
Passados aproximadamente 10 (dez) anos da instauração da Lei n 12.305/10, e aproximadamente 2 (dois) anos da sanção do Decreto Municipal N 18061, de 18 de outubro de 2018, observa-se que os avanços são considerados pequenos diante das inúmeras falhas no controle e fiscalização da gestão de resíduos sólidos. Ademais, a baixa adesão por parte das empresas e da população contribuem para que a destinação correta dos resíduos ainda apresenta baixos quantitativos. Tendo em vista que o poder público enfrenta dificuldades quanto à realização e aplicação de novas políticas públicas, a implementação de parcerias público-privadas (PPP's) poderia contribuir para o estabelecimento consistente da gestão compartilhada. Seria uma alternativa viável, possibilitando a diminuição de custos para o município e permitindo a inclusão de mais empresas no processo de manejo de resíduos.

A realização do estudo destaca a importância da implementação de ações previstas em instrumentos legais, favorece a exploração do debate e contribui para análise da responsabilidade compartilhada dentro dos sistemas de logística reversa. Ressalta-se a importância de se analisar processos em andamento, captando as dificuldades de implementação que muitas vezes desaparecem quando se trata de relatos ex-post facto.

A pesquisa possui limitações importantes, sendo a principal a ausência de dados relativos ao mercado. Por ser um processo ainda em formação, tanto as informações como as fontes ainda estão por serem mapeadas. Isto restringe o uso de instrumento de dados primários junto a atores que não o poder público. A busca por dados secundários na internet, sem uso de repositórios institucionais hierarquizados, compromete a representatividade e confiabilidade das informações, requerendo que a análise considere a existência, ou não, do fato, e não o conteúdo em si. Por fim, o momento em que a pesquisa estava em execução ocorreu no período de isolamento social provocado pela COVID-19, o que impossibilitou o acompanhamento da ação das empresas pioneiras.

Como recomendações, tem-se tanto uma análise dos dados secundários referentes aos volumes coletados e tratados, que denotam o amadurecimento do sistema, quanto a realização de pesquisas qualitativas que acompanhem a formação do mercado privado, envolvendo empresas, cooperativas e movimentação social de conscientização e ação referente a redução e reaproveitamento dos resíduos urbanos.

\section{REFERÊNCIAS}

ABRELPE - Associação Brasileira de Empresas de Limpeza Pública e Resíduos Especiais. Panorama dos Resíduos Sólidos no Brasil - 2018/2019. São Paulo, 2019. Disponível em: <https://abrelp.org.br/panorama/>. Acesso em: 15 ago. 2020. 


\section{Gestãoe \\ Desenvolvimento}

e-ISSN: 2446-6875

p-ISSN: $1807-5436$

ALVES, Ricardo Ribeiro. Administração Verde: O caminho sem volta da sustentabilidade ambiental nas organizações. 1. ed. Rio de Janeiro: Elsevier, 2016.

BORGES, Alexandre Walmott. MELLO, Giovanna Cunha. OLIVEIRA, Mário Angelo. Mecanismos Garantidores do Direito Fundamental ao Ambiente na Política Nacional de Resíduos Sólidos: análise dos princípios do Poluidor-Pagador e do Protetor-Recebedor. Veredas do Direito, v. 7, n. 13/14, p. 191-212, Belo Horizonte, 2010.

BRASIL. Lei n 12.305, de 02 de agosto de 2010. Institui a Política Nacional de Resíduos Sólidos. Brasília: Presidência da República: Casa Civil, 2010a.

BRASIL. Decreto $\mathbf{n}^{\mathbf{7}} \mathbf{7 . 4 0 4}$, de 23 de dezembro de 2010. Regulamenta a Lei n² 12.305, de 2 de agosto de 2010, que institui a Política Nacional de Resíduos Sólidos; cria o Comitê Interministerial da Política Nacional de Resíduos Sólidos e o Comitê Orientador para a Implantação dos Sistemas de Logística Reversa; e dá outras providências. Brasília: Presidência da República, 2010b.

CARVALHO, M. S. F. C.; CARVALHO, C. P. Discursos sobre a mulher no webjornalismo piauiense: análise crítica das notícias dos portais Cidade Verde e G1/PI. Revista Observatório, v. 4, n. 1, p. 779-802, 2018.

CERVO, Amado L.; BERVIAN, Pedro A. Metodologia científica. 5. ed. São Paulo: Prentice Hall, 2002.

COELHO, João Paulo Ferreira. Análise do Sistema de Gestão e Gerenciamento de Resíduos Sólidos Urbanos na Cidade de Teresina-PI. 2019. 119 f. Orientador: Prof. Dr. Denis Barros de Carvalho. Dissertação (Mestrado Profissional em Gestão Pública) - Universidade Federal do Piauí, Teresina, 2019.

COOPER, Donald R.; SCHINDLER, Pamela S. Métodos de pesquisa em administração. 10a ed. Porto Alegre: Bookman, 2011.

CORRÊA, Henrique Luiz. XAVIER. Lúcia Helena. Sistemas de Logística Reversa: criando cadeias de suprimentos sustentáveis. São Paulo: Atlas, 2013.

Gestão de resíduos sólidos são desafios para empresas em Teresina. Portal O Dia. Teresina, 09 de agosto de 2019. Disponivel em: <https:www.portalodia.com/amp/noticias/politica/novas-regras-para-gestao-de-residuos-impoem-desafio-a-empresas-na-capital-368110.html>. Acesso em 13 set. 2020.

INSTITUTO ETHOS DE EMPRESAS E RESPONSABILIDADE SOCIAL. Princípios e Critérios para Implementação de Alianças Público-Privadas na Gestão de Resíduos Sólidos: como ações baseadas na colaboração entre os diversos atores sociais podem atender diretrizes da Política Nacional de Resíduos Sólidos (Lei 12.305/2010). São Paulo, 2015. Disponivel em: <https://www.ethos.org.br/cedoc/princi- 


\section{Gestãoe \\ Desenvolvimento}

e-ISSN: 2446-6875

p-ISSN: $1807-5436$

pios-e-criterios-para-implementacao-de-aliancas-publico-privadas-na-gestao-de-residuos-solidos/>. Acesso em: 15 ago. 2020.

LEITE, Paulo Roberto. Logística Reversa: meio ambiente e competitividade. 2. ed. São Paulo: Pearson Prentice Hall, 2009.

Lixo Zero identifica aumento de infraç̃̃es por descarte irregular no início de 2020. Prefeitura Municipal de Teresina, Teresina, 19 fev. 2019. Disponivel em: <https://pmt.pi.gov.br/2020/02/19/lixo-zero-identifica-aumento-de-infracoes-por-descarte-irregular-no-inicio-de-2020/>. Acesso em: 15 ago. 2020.

MACÊDO, Moema Luisa Silva. ROHLFS, Daniela Buosi. Responsabilidade Compartilhada, Logística Reversa e cadeias com obrigatoriedade imediata no âmbito da Política Nacional de Resíduos Sólidos. Pontifícia Universidade Católica de Goiás, Programa de Pós-graduação em Vigilância Sanitária. 2013. Disponivel em: <www.cpgls.pucgoias.edu.br/8mostra/Artigos/SAUDE\%20E\%20BIOLOGICAS/Responsabilidade\%20Compartilhada,\%20Log\%C3\%ADstica\%20Reversa.pdf>. Acesso em: 20 jul. 2020.

MANCINI, Sandro Domini; FERRAZ, Lázaro Ferraz; BIZZO, Waldir Antônio. Resíduos Sólidos. In: ROSA, André Henrique; FRACETO, Leonardo Fernandes; MOSCHINI-CARLOS, Viviane (Orgs.). Meio Ambiente e sustentabilidade. Porto Alegre: Bookman, 2012.

MARIATH, Anelice Kotz; SCHMITT FIGUEIRÓ, Paola. Sustentabilidade com Foco na Logística Reversa da Indústria de Tintas e Vernizes. Revista Gestão e Desenvolvimento, Novo Hamburgo, v. 15, n. 1, p. 127-144, jan. 2018. ISSN 2446-6875. Disponível em: <https://periodicos.feevale.br/seer/index.php/ revistagestaoedesenvolvimento/article/view/1143/2146>. Acesso em: 28 fev. 2021. DOI: https://doi. org/10.25112/rgd.v15i1.1143.

MICHEL, Maria Helena. Metodologia e pesquisa científica em ciências sociais: um guia prático para acompanhamento da disciplina e elaboração de trabalhos monográficos. 2. ed. São Paulo: Atlas, 2009.

MOREIRA, Danielle de Andrade et al. Responsabilidade Ambiental Pós-consumo à Luz do Princípio do Poluidor-Pagador: uma análise do nível de implementação da responsabilidade compartilhada pelo ciclo de vida dos produtos prevista na política nacional de resíduos sólidos. Revista de Direito da Cidade, vol. 08, n. 4. ISSN 2317-7721, pp. 1442-1467, 2016.

OLIVEIRA, Rodrigo Martins Campos. Sustentabilidade econômica na gestão de resíduos sólidos: fatores críticos de sucesso para replicação no Brasil de incentivo econômico por meio do sistema Pay-As-You-Throw. 2018. 170 f. Orientador(a): Annelise Vendramini. Dissertação (MPGC) - Escola de Administração de Empresas de São Paulo, São Paulo, 2018. 


\section{Gestãoe \\ Desenvolvimento}

e-ISSN: 2446-6875

p-ISSN: $1807-5436$

ROGERS, Dale S.; TIBBEN-LEMBKE, Ronald S. Going Backwards: Reverse logistic trends and practices. Reverse Logistic Executive Council, 1998. Disponivel em: <http://www.rlec.org/reverse.pdf>. Acesso em: 14 jan. 2021.

Saiba quais são os cinco sites de notícias mais acessados do Piauí. Em Foco. Campo Maior, 22 de jun. de 2020. Disponivel em: <https://www.campomaioremfoco.com.br/noticia/12277/Saiba-quais-sao-os-cinco-sites-de-noticias-mais-acessados-do-Piaui>. Acesso em: 14 jan. 2021.

Saiba quais os sites de notícias mais acessados do Piauí em 2020. Voz do Piauí. Piripiri, 08 de abr. de 2020. Disponível em: https://vozdopiaui.com/noticia/95/saiba-quais-os-sites-de-noticias-mais-acessados-do-piaui-em-2020>. Acesso em: 14 jan. 2021.

SINNOTT, Alice Pereira. A aplicabilidade da Lei N 12.305/10 sob o viés do princípio da responsabilidade compartilhada. Rio Grande do Sul: PUC-RS/Faculdade de Direito, 2012.

TERESINA. Prefeitura Municipal. Lei n⿳ 4.474/13. Institui o "Programa Lixo Zero", no âmbito do município de Teresina, e dá outras providências. 2013. Disponível em: <http:http://200.23.153.37/acervodigital/ norma/lei-4474-2013>. Acesso em: 15 ago. 2020.

TERESINA. Prefeitura Municipal. Lei $\mathbf{n}^{\mathbf{4}} \mathbf{4 . 9 7 4 / 1 6}$. Institui o novo Código Tributário do município de Teresina e dá outras providências. 2016. Disponível em: <http://200.23.153.37/acervodigital/norma/lei-complementar-4974-2016>. Acesso em: 15 ago. 2020.

TERESINA. Prefeitura Municipal. Decreto n 18.061/2018. Regulamenta o art. 112, da Lei Complementar $n^{\circ}$ 3.610, de 11 de janeiro de 2007 (Código de Posturas), para disciplinar o cadastramento de empresas transportadoras de resíduos sólidos. no âmbito do Município de Teresina, e dá outras providências. 2018a. Disponivel em: <https://semduh.teresina.pi.gov.br/documents/decreto-no-18061-2018/>. Acesso em: 10 set. 2020.

TERESINA. Prefeitura Municipal. Decreto 18.062/2018. Regulamenta o art. 120, § 3º da Lei Complementar $n^{\circ}$ 3.610, de 11 de janeiro de 2007 (Código de Posturas), para disciplinar o cadastramento das áreas de destinação de resíduos sólidos, no âmbito do Município de Teresina, e dá outras providências. 2018b. Disponivel em: <https://semduh.teresina.pi.gov.br/documents/decreto-no-18062-2018/>. Acesso em: 10 set. 2020.

TERESINA. Prefeitura Municipal. Plano Municipal de Gestão Integrada de Resíduos Sólidos de Teresina - PI. 2018. Disponivel em: <https://semplan.teresina.pi.gov.br/wp/content/uploads/sites/39/2018/09/ PLano-Municipal-de-Gestão-Integrada-de-Resíduos-Sólidos-de-Teresna.pdf>. Acesso em: 10 set. 2020. 


\section{Gestãoe \\ Desenvolvimento}

e-ISSN: 2446-6875

p-ISSN: 1807-5436

TORRES, Osmar et al. Atitudes e Formação de Consciência Ambiental: Um estudo sobre as implicações de um Programa de Coleta Seletiva de Resíduos Sólidos em Campo Grande-MS. Revista Gestão e Desenvolvimento, Novo Hamburgo, v. 13, n. 1, p. 144-155, jan.2016. ISSN 2446-6875. Disponível em: <https://periodicos.feevale.br/seer/index.php/revistagestaoedesenvolvimento/article/view/283/391>. Acesso em: 28 fev. 2021. DOI: https://doi.org/10.25112/rgd.v13i1.283.

VIANA, T. D.; COELHO, T. F.; RÊGO, A. R. A imagem da Universidade Federal do Piauí na Mídia Impressa e Eletrônica Piauiense. In: XIII Congresso de Ciências da Comunicação na Região Nordeste, 2011, Maceió. Anais... Maceió: INTERCOM, 2011. 